\title{
Endovenous ablation of refluxing saphenous and perforating veins
}

\author{
Thomas Proebstle ${ }^{1,2}$ and Renate van den Bos ${ }^{3}$ \\ Department of Dermatology, University Medical Center Mainz, Germany \\ Private Clinic Proebstle, Mannheim, Germany \\ Department of Dermatology, Erasmus University Medical Center, Rotterdam, The Netherlands
}

\begin{abstract}
Summary: Since the end of the nineties endovenous thermal ablation and more recently non-thermal, non-tumescent techniques have been developed and improved. Until now, because of their favourable side effect profile in conjunction to sustained efficacy, in many countries they already replaced high ligation and stripping in the treatment of refluxing saphenous veins as well as for treatment of perforators and selected tributaries. Now, studies and comparative trials are available with long-term follow-ups for most of the techniques, providing valid data on occlusion and reflux rates, side effect profiles, and health related quality of life.
\end{abstract}

Keywords: Endovenous laser, radiofrequency ablation, thermal ablation, cyanoacrylate, saphenous vein, endovenous ablation

\section{Introduction}

Venous disease frequently affects patients' health-related quality of life (HRQOL) with substantial clinical symptoms like pain, heaviness, itching, cramps, and tired legs. These symptoms are usually already present in the early stage of venous disease. For standardized descriptions of venous complaints, clinical and haemodynamic abnormalities, the physician's Venous Clinical Severity Score and the CEAP-classification can be used [1]. The most commonly used disease-specific HRQOL tools for varicose veins and more advanced stages of CVD are the Aberdeen Varicose Vein Questionnaire (AVVQ) [2], the Chronic Venous Insufficiency Quality of Life Questionnaire (CIVIQ) [3], the specific quality of life and outcome response - venous (SQOR_V) [4] or the Venous Insufficiency Epidemiological and Economic Studies (VEINES) [5] questionnaire. Chronic stages of venous disease are the result of chronic venous congestion and at least partially irreversible once eczema, hyperpigmentation, lipodermatosclerosis or leg ulcers, as described by the CEAP classification [6], have occurred. Besides improvement of symptoms and prevention of chronic stages of venous disease, the treatment of varicose veins is aiming towards prevention of acute complications as well. Such complications are bleeding, superficial venous thrombosis, deep venous thrombosis (DVT), and pulmonary embolism.

Once patients' complaints or their cosmetically disturbing varicose veins brought them into the office of a phlebologist, duplex examination is often able to demonstrate reflux in the venous system which can be addressed by conservative, surgical or interventional treatment options.
While a conservative approach with medical elastic compression stockings has never gained much popularity amongst younger patients, surgical or interventional treatment of varicose veins belong to the most frequently performed operations in developed health care systems.

The need for less invasive, cosmetically superior treatment modalities has led to the introduction of minimally invasive, endovenous techniques around the year 2000. The main benefits to these techniques are the fact that there is no need of spinal or general anaesthesia, because they are performed with local tumescent anaesthesia, and that success rates as well as recurrence rates are at least similar if not more favourable compared to classic surgery [7]. These endovenous techniques are usually based on thermal action and they radically changed the treatment of varicose veins. Endovenous thermal ablation (EVTA) therapies based on radiofrequency (RFA), laser (EVLA) or steam (EVSA) have become the most frequently used type of therapy for saphenous varicose veins, particularly in countries where reimbursement of the procedure has been introduced. In the meantime, EVTA has been ranked superior to surgery and superior to foam sclerotherapy by scientific societies as well as by reimbursement directing government affiliated institutions, based on the evidence from multiple case-series and randomized controlled trials (RCTs) which show that EVTA leads to high success rates and very few treatment induced side-effects [8-10].

A recent large worldwide survey amongst experienced physicians evaluated how patient characteristics and duplex ultrasound (DUS) findings influence management decisions of physicians with specific expertise in the field of chronic venous disease. In this survey, physicians also 
recommended EVTA as first choice treatment. Patient characteristics, such as older age, peripheral arterial disease, and high body mass index were considered relevant in altering the management strategy. In these patients the treatment choice often was a less invasive approach, with fewer phlebectomies, more UGFS (ultrasound guided foam sclerotherapy) of tributaries, and more MECS (medical elastic compression stockings). In particular, in cases of arterial disease "no treatment" became a frequently preferred option. Also, DUS findings influenced the preferred treatment strategy. Terminal valve competence and a small diameter of $<4 \mathrm{~mm}$ of the GSV made physicians prefer to spare the saphenous vein and treat tributaries only [11].

The first FDA approved EVTA procedure was the RFAbased VNUS Closure Plus system [12] followed shortly thereafter by EVLA. Later on, technological advances led to radiofrequency segmental thermal ablation (RSTA) [13] and introduction of higher laser wavelengths as well as development of radial [14], covered laser fibre tips [15] or tulip tipped catheters [16]. In addition, steam was used as an alternative heat source [17]. More recently nonthermal, non-tumescent techniques like endovenous cyanoacrylate embolization [18] or mechano-chemical ablation [19] have joined the already established endothermal ablation techniques.

\section{General considerations on endothermal treatments}

Most importantly if not crucial in endothermal ablation of refluxing veins is the delivery of sufficient energy doses to the vein wall to achieve a reliable and durable occlusion of the treated vein. The concept of linear endovenous energy density (LEED: delivered energy in Joule per $\mathrm{cm}$ vein length) and endovenous fluence equivalent (EFE: delivered energy in Joule per $\mathrm{cm}^{2}$ of inner vein wall surface) was shown to correlate with occlusion and early reopening of treated veins [19]. A lower limit of $25 \mathrm{Joule} / \mathrm{cm}^{2}$ for EFE was recommended [21] along with a LEED of $80 \mathrm{~J} / \mathrm{cm}$ or more [22]. Similarly the efficacy of radiofrequency segmental ablation was linked to even higher values for LEED and EFE in the range of 71.4 to $143.3 \mathrm{~J} / \mathrm{cm}$ or 38 to $192 \mathrm{~J} /$ $\mathrm{cm}^{2}$, respectively [13].

While the administered endovenous energy dose is responsible for the success of endovenous ablation, the power density seems to be related to side effects of endothermal ablation. For example, while in a bare laser fibre the energy is delivered through a flat cut tip with a diameter of less than half a square millimetre, in radiofrequency segmental thermal ablation (RSTA) the energy is delivered through a catheter surface of several square centimetres. A larger surface simply means that the same energy dose could be delivered with much less power density. A bare fibre exceeds the threshold of $1 \mathrm{~kW} / \mathrm{cm}^{2}$, resulting in tissue ablation and cutting of the vein wall, while in RSTA energy is delivered with a power density of less than $10 \mathrm{~W} /$ $\mathrm{cm}^{2}$. Sophisticated laser fibre tips like the tulip, the covered or the radial type, try to imitate this behaviour by increasing the target surface of laser energy at the vein wall, also reducing the power density this way. Fibre tip design seems to be more important for a smooth recovery from endovenous laser ablation than the choice of a certain laser wavelength [23].

Another matter of discussion since the introduction of endothermal ablation has been whether treatment of tributaries by phlebectomies or sclerotherapy should be performed at the time of saphenous vein treatment or at a later stage when combined treatment is preferred. There are publications supporting both positions, the most recent ones favour the simultaneous treatment [24]. Another concept that gained some attention is the idea that saphenous reflux may diminish when treating tributaries only. In certain patients, phlebectomies of saphenous tributaries may only results in a competent saphenous vein, making ablation of the saphenous vein unnecessary. Side effects of endothermal ablation, such as pain or bruising, are generally mild and allow return to normal activity the next day. In a manufacturer's registry, over a period of five years, the complication rate was low with $<1: 2,500$ deep vein thrombosis, <1:10,000 pulmonary embolism, and $<1: 50,000$ death [25]. However, numbers are higher according to insurance companies' databases, revealing thrombotic complications in more than 130,000 patients within 30 days after an intervention for varicose veins. The estimated risk for DVT was $4.4 \%$ for radiofrequency ablation and 3.1\% for laser ablation, the risk of pulmonary embolism was $0.3 \%$ for both methods [26].

Follow-up including DUS is recommended after EVTA. Time until the first follow-up may vary between one and six weeks. The consensus document on EVTA recommends a clinical follow-up and DUS examination within 10 days and a clinical as well as DUS review of treatment results within three to six months [27]. Routine prescription of prophylactic anticoagulants is not needed, as the risk of VTE is very low (0-2\%). However, patients' risk should be stratified; if a high risk of VTE is present (age $>60$, obesity, immobility, oral contraceptive or hormone replacement therapy use, cancer, history of superficial or deep venous thrombosis, or a known severe thrombophilia), one should consider prophylactic use of low molecular weight heparin, starting at the day of the procedure until 10-14 days after. Risk assessment should be based on local, hospital or national guidelines or the Caprini's assessment method can be applied [28].

A pragmatic approach is used by one of the authors: To lower the risk for the patients as much as possible, they are set on LMWH until the first duplex ultrasound control examination of the treated vein, of the deep vein system, and particularly of the junction of both is completed. This examination is actually scheduled within the first 72 hours after EVTA. However, studies supporting such a strict schedule are missing. 


\section{Endovenous laser ablation}

Frequently, endovenous laser ablation is performed as an outpatient procedure using tumescent anaesthesia. Venous access is usually obtained under DUS guidance by puncturing the vein with $16 \mathrm{G}$ or $18 \mathrm{G}$ needles at the distal point of reflux. Depending on the nature of the laser fibre tip, it may be necessary to place a full-length guide wire and sheath below the saphenofemoral junction (SFJ). The most important step in the EVLA procedure is positioning the tip of the laser fibre 1 to $2 \mathrm{~cm}$ distally from the SFJ, using DUS visualization. In case of treatment of a small saphenous vein (SSV), the fibre tip is usually propagated towards the popliteal vein as long as the SSV still remains at the immediate subfascial level. Depending on the length of the treated vein, about 250 to $500 \mathrm{~mL}$ of tumescent local anaesthesia (TLA) is injected perivenously under DUS guidance. TLA usually contains $1 \mathrm{mg}$ epinephrine and 500-700 mg lidocaine or prilocaine per $1000 \mathrm{~mL}$ saline solution. A mechanical infusion pump is highly recommended. Tumescent local anaesthesia is warranted because it reduces pain, cools perivenous tissue, and decreases the venous diameter. Moreover it provides anaesthesia for several hours after the intervention. A precooled TLA may enhance the analgesic effect [29]. During the release of laser energy, the laser fibre is pulled back continuously with a speed of about $3-5 \mathrm{~mm} / \mathrm{s}$, however, the pullback can be performed gradually as well, when using lasers with pulsed energy. The velocity of the pullback depends on the laser power engaged and the vein diameter to deliver the intended amount of laser energy per $\mathrm{cm}$ vein length, resembling linear endovenous energy density (LEED). An endovenous fluence equivalent (EFE) of at least $25 \mathrm{~J} / \mathrm{cm}^{2}$ is recommended to achieve a sustained occlusion [21]. For example,an average vein with a diameter of about $8 \mathrm{~mm}$ demands a laser power of $15 \mathrm{~W}$ and a pullback speed of $2 \mathrm{~mm} / \mathrm{s}$ which result in a LEED of $75 \mathrm{~J} / \mathrm{cm}$ and an EFE of $29.9 \mathrm{~J} / \mathrm{cm}^{2}$. EFE is calculated by dividing LEED by the vein circumference in $\mathrm{cm}$.

\section{Parameters}

Variables in endovenous laser treatment include laser wavelength, laser power, fibre pullback speed, and fibre type ().

Almost all studies that have been published on EVLA show very high success rates (>90\%), independently of laser wavelength. The first case series suggesting that EVLA might be successful for treating large varicose veins were published in 2001 [30, 31]. Thereafter, multiple case series have been presented and systematic reviews have been published $[32,33]$. In a prospective study, $93 \%$ of 499 GSVs were occluded two years after therapy. An Italian workgroup reported a success rate of $97 \%$ in 1,000 patients with a follow-up of three years, and another large study of more than 1,250 limbs showed a success rate of approximately 95\% [34-36]. A four-year follow-up study of EVLA combined with ambulatory phlebectomies for the treatment of superficial venous incompetence showed re- currence rates of $4.3 \%$ at four years, $3.6 \%$ at two years, and $5.9 \%$ at one year. [37] A meta-analysis showed that EVLA was significantly more effective than stripping, UGFS, and ClosurePlus-RFA [7]. The recently published randomized clinical trial of Rasmussen et al. showed that stripping, EVLA, and RSTA were equally effective [38]. Several other RCTs with long-term follow-up have proven the durable success of EVTA [39].

The first studies of EVLA report the use of $810 \mathrm{~nm}$ diode wavelength, targeting haemoglobin. Subsequently, other haemoglobin targeting wavelengths were introduced $(940,980,1,064 \mathrm{~nm})$ followed by higher wavelengths $(1,320,1,470,1,500,1927$, and $2,100 \mathrm{~nm}$ with water/vein wall as main target), however all the wavelengths are absorbed in varying degrees by blood constituents which can be either water or haemoglobin. All currently available wavelengths are successful in ablation of varicose veins. Success rates of EVLA are very high almost regardless of the amount of energy delivered as already described above. Unfortunately, studies that compare different levels of energy administered per centimetre, aiming to find the adequate dose needed for durable vein occlusion, are lacking. The first decade after the introduction of EVLA, most studies reported the use of a bare fibre tip combined with different laser wavelengths. Other fibre tip designs have been introduced since all of them aim to prevent direct contact of the fibre tip with the vein wall and thereby decrease the amount of vein wall perforations which may lead to pain and bruising. A radial fibre with radial emission of laser light has been combined with a wavelength of $1,470 \mathrm{~nm}$ showing good results [14, 40]. One study reported the results with a covered fibre tip, which has a metal tube-case and a glass weld at the distal tip, showing slightly lower occlusion rates than a bare tip [15]. One of the most recent inventions is the tulip tip that is designed to prevent perforations by centring the laser fibre within self-expandable blades $[16,41]$ and the 2-ring-radial fibre which proved to cause less pain during the first two weeks after EVLA compared to the 980 nm-bare-fibre combination [42].

\section{Radiofrequency ablation}

The procedure is very similar to EVLA. Access to the varicose vein is obtained with a micropuncture set and a $7 \mathrm{~F}$ sheath under DUS guidance, typically at the distal point of reflux. The pioneering Closure Plus catheter (VNUS Medical Technologies, Inc., Sunnyvale, Calif), mainly in use between 1999 and 2007, is positioned 1 to $2 \mathrm{~cm}$ distally from the junction under longitudinal DUS visualization. However, due to its slow pullback speed it has been quickly replaced after the introduction of radiofrequency segmental thermal ablation (RSTA) [13]. It has a $7 \mathrm{~cm}$ therapeutic distal tip that heats up to $120^{\circ} \mathrm{C},[26]$ and the first case series of 252 treated GSVs showed an occlusion rate of $99.6 \%$ (Figure 1.) [13]. Follow-ups after five years 
also showed durable and high occlusion rates of $91.9 \%$, with $94.9 \%$ free of reflux [43]. In 2012, a catheter with analogue function and a $3 \mathrm{~cm}$ heating element was introduced to treat vein segments too short to allow for placement of a $7 \mathrm{~cm}$ heating element. Bipolar radiofrequency induced thermotherapy also known as the RFITT technology (Olympus Medical Systems, Hamburg, Germany) has a bipolar arrangement with blood and the venous wall as a conductor between the two poles. The applicator tip delivers energy directly to the surrounding blood and tissue (heating up to 60-100 C). In contrast to segmental thermal ablation, the applicator itself is not heated and energy delivery is not temperature- but impedance-driven, as the catheter was originally developed to ablate solid tumours by induction of heat necrosis in a stationary fashion, not moving the catheter during energy delivery. Acceptable occlusion rates have been reported but energy dosing may pose a problem in larger veins [44, 45], also users are still trying out alterations in the current treatment protocol [46]. Despite the fact that RFITT was introduced for endovenous ablation more than 10 years ago, papers reporting long-time results are still lacking. Small short-term comparative studies suggest that EVLA and RFA are equally effective compared to vein stripping but are more appreciated by patients [47]. Because minimally invasive techniques seem to be less associated with recurrences and neovascularization, long term studies may show a clinical benefit to these new procedures compared to ligation and stripping [7], especially for the treatment of the SSV [48]. Recurrence patterns after EVTA are slightly different from recurrences after surgery. One RCT studied the recurrence patterns after high ligation along with stripping and EVLA after five-years of followup. Overall the recurrence rate was similar, but SFJ reflux and same-site recurrences occurred more often after EVLA, however, different-site (new) recurrences were more often seen after surgery [49]. Segmental RFA seems to be equally effective as EVLA, but may be associated with less post-procedural pain than EVLA [50].

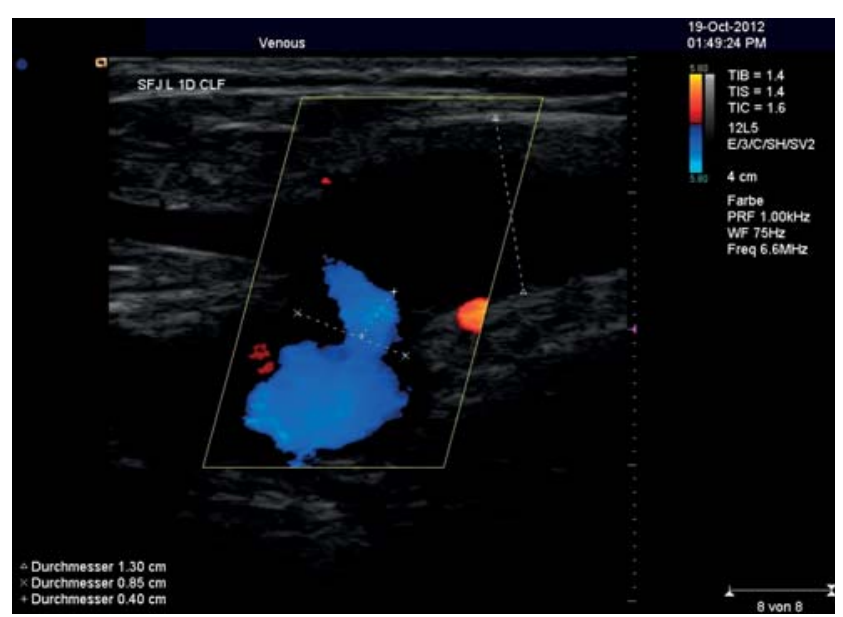

Figure 1. Ultrasound image of the saphenofemoral junction with a $13 \mathrm{~mm}$ diameter GSV day one after segmental thermal ablation.

\section{Steam ablation}

Endovenous steam ablation is another method of thermal vein ablation, which is relatively new and not very frequently used. It works by heating the vein wall and its contents with steam at a temperature of maximal $120^{\circ} \mathrm{C}$. The procedure of steam ablation is very similar to the other endovenous techniques. The vein is punctured with a 16-gauge needle or cannula under DUS guidance. The GSV is usually entered at the distal site of reflux and the SSV is usually punctured mid-calf, depending on vein diameter and extent of reflux. To prevent sural nerve injury, it is advisable to avoid puncturing the SSV in the lower third of the calf. The steam catheter $(1.2 \mathrm{~mm}$ diameter $)$ is passed through the hollow needle into the vein and the echo-dense tip of the catheter is then carefully positioned at approximately $2-3 \mathrm{~cm}$ from the junction under DUS guidance. About 250 to $500 \mathrm{~mL}$ (depending on the length of the vein treated) of tumescent anaesthesia is administered around the vein within the fascia blades under DUS guidance. Because the steam is ejected perpendicular to the catheter with quite high pressure, it seems that more tumescent anaesthesia is needed compared to other EVTA treatments in order to avoid the sensation of heat or pain. After activation, the catheter releases small puffs of steam, and is gradually pulled back. At first activation, four puffs of steam should be administered, while gentle manual pressure is exerted on the junction. Depending on the diameter of the vein, two or three puffs of steam can be administered every following centimetre. It is advisable to continue applying manual compression on the junction during the first $4 \mathrm{~cm}$ of the treated area, as the steam is ejected with pressure and can therefore reach several centimetres beyond the catheter tip.

\section{Parameters}

The device suitable for steam ablation is Steam Vein Sclerosis $^{\circledast}$ (SVS system; CERMA SA, France). This system consists of a generator and a connected hand piece. The catheter attached to the hand piece delivers the steam with a temperature of around $120{ }^{\circ} \mathrm{C}$ into the vein to be treated. The tip of the catheter has two holes with a diameter of $0.15 \mathrm{~mm}$ on the side of which the pulses of steam are released. Because the treatment is not frequently used and its costs are not reimbursed in many countries, there are very few publications on steam ablation [17, 51]. These studies show preliminary good occlusion rates. The first RCT on steam ablation versus laser ablation included more than 200 GSVs and it showed non-inferior occlusion rates, but slightly lower post-operative pain scores and shorter convalescence after steam ablation [52]. All EVTA treatments have in common that their effectiveness depends primarily on the amount of energy delivered to the vein wall $[21,53]$. The first study on steam ablation showed that there were recanalizations which might be related to underdosing. An experimental study showed that administering one pulse per centimetre is not leading to a homogeneous temperature profile, where- 
as three pulses per centimetre did [54]. The RCT also showed that the occlusion rates in patients treated with highdose were better than in those treated with low-dose.

\section{Indications of endovenous thermal ablation}

The EVTA treatments all have in common that they can be performed in an outpatient setting using local tumescent anaesthesia. Patients are recommended to wear medical elastic compression stockings for one week after all treatments. Every treatment requires DUS experience, and in most cases, at least in Europe, DUS visualization during the procedure is performed by the physicians themselves. Because of the rigidity and size of the disposables, linear primary saphenous veins with a diameter of at least $3 \mathrm{~mm}$ are most suitable for EVLA. If thinner fibres are used, EVLA can be used for more tortuous veins such as parts of tributaries and perforator veins [55]. However, one should be careful with treating varicose veins that had a previous superficial thrombosis or were previously treated with foam sclerotherapy, as introducing the laser fibre may be difficult. The indications for RFA are comparable to EVLA. However, treating tortuous and relatively small varicose veins can be difficult and one should be careful to avoid vein wall perforations. Endovenous steam ablation can be used in saphenous varicose veins but also in tributaries, as the steam catheter is small, flexible, and the ejected steam can reach several centimetres. Of all EVTA techniques steam ablation may be the treatment of choice for recurrences after stripping, as these veins are usually tortuous and the steam catheter is very flexible. Also steam may find its way easier into side branches and loops. However, in our experience, ultrasound-guided foam sclerotherapy is usually the first treatment choice for tortuous recurrences after stripping.

\section{Non-thermal, non-tumescent ablation of saphenous veins}

While liquid and foam sclerotherapy for ablation of saphenous veins seem to be less successful and durable than endothermal techniques, and because the administration of tumescent local anaesthesia needs time and is associated with side effects like bruising, there has been a demand for non-tumescent, non-thermal techniques [56].

Mechano-chemical ablation (MOCA) is a catheter based system which should strip-off the endothelium of the vein using a rotating wire at its tip while liquid sclerosant is administered concomitantly. A system which does not need local anaesthesia apart from the local anaesthesia administered at the puncture site [19]. It is unknown whether this treatment results in durable vein occlusion, as long-term results are not yet published. A disadvantage is that the system allows treatment of only one saphenous vein in a 24 hour period, because of dose limitations of sclerosing agents. Moreover, wearing medical elastic compression stockings for one week after treatment is still recommended. Nevertheless, when looking at pain scores during and along the first weeks after the intervention, MOCA outperforms RSTA [57]. Treating refluxing saphenous veins by cyanoacrylate ablation (CA) is the most recent development in non-tumescent, non-thermal ablation [58, 59] which overcomes even some of the limitations of MOCA. While both, MOCA and CA do not cause paraesthesia, in contrast to MOCA, CA is lacking a dose limit, allowing the simultaneous treatment of up to four saphenous veins in the same session. In addition, CA does not necessarily require medical compression stockings after the intervention and it has been reported to be at least equally effective as RSTA after three months follow-ups [60]. However, long-term follow-up data for CA as well are still lacking.

\section{Treatment of refluxing perforator veins}

Treatment of incompetent perforator veins is not recommended in patients with mild CVD. At present, there is no compelling level 1 evidence to provide a grade A recommendation that the treatment of incompetent perforator veins alone affects venous ulcer healing or recurrence. However, perforator treatment in combination with superficial vein ablation can be considered in patients with venous ulcers [61]. Endovenous treatment of perforator veins is more challenging than treatment of saphenous veins, because of the tortuosity, deep location, and short segment of the vein to be treated. Cannulation can also be more difficult, because perforating veins are often located in areas of sclerotic skin or ulcers. In addition, it is more difficult to apply the tumescent anaesthesia carefully around the perforator vein. Closure rates are reported to be lower than for saphenous veins, varying from $59 \%$ to $90 \%$ [62]. For RFA a special perforator stylet with a short heating element is available [63]. The treatment procedure of perforator veins with EVLA is similar to the procedure of saphenous veins, no other device is needed [64]. One study reports on ablation with CA of 33 incompetent perforator veins with $76 \%$ occlusion rate, showing no serious complications [65].

\section{Position endovenous thermal and non-thermal ablation therapies}

The introduction of EVTA techniques almost 20 years ago has radically changed the approach to the treatment of varicose veins. Finally very effective treatments with a mild 
side-effect profile are available. The occlusion rates of the current EVTA treatments is excellent $(>90 \%)$. Also, sideeffects are mild, convalescence is very short and serious complications are rare. These favourable outcomes have led to a rapid increase in the use of EVTA and a significant decrease in the frequency of conventional ligation plus stripping. One should, however, try to address the remaining questions concerning the exact working mechanisms. Also, there is still a lack of knowledge on long-term effects of the different treatments, not only in terms of efficacy. The type and frequency of potential recurrences many years after EVTA will need attention and investigation. The long-term effect of carbonized products that remain inside the body after EVLA is not known either. Although there are some RCTs with five-year follow-ups, longer follow-up data would be interesting, in order to learn about the differences in durable efficacy of the different treatment options. Furthermore, dose-finding studies are needed to assess the optimal treatment parameters, especially for EVSA. But EVLA as well does not have a standardized protocol yet. Several advantages and disadvantages of the three different EVTA techniques can be summarized based on the available literature and on personal experience (Table I). We should also incorporate cost-effectiveness in our treatment strategy, as this is an increasingly important aspect in treatment choice, especially in countries where reimbursement of EVTA is lacking. Several publications support the hypothesis of the ascending etiology of varicose disease, starting from the distal superficial venous network [66]. The surgical approach focusing on the treatment of tributaries by phlebectomies and simultaneous preservation of the saphenous vein is enjoying renewed attention. Treating insufficient tributaries of the insufficient saphenous vein may lead to abolition of the saphenous reflux, so the saphenous vein could be saved. One prospective study with 100 patients with a refluxing GSV plus a refluxing tributary showed that one year after treatment of tributaries with only phlebectomies, the GSV was reflux-free in $50 \%$ of patients [67]. This concept challenges the current opinion on the treatment of venous insufficiency, which is usually primarily aimed at treating the refluxing saphenous vein. A selected group of patients may be better off with a less invasive treatment with phlebectomies only. Another group of patients, probably with more advanced diseases (e.g., junctional reflux, large segment of GSV reflux, large GSV diameter etc.) may benefit more from a combined treatment. To select the right treatment strategy for the individual patients, the patient characteristics, which can predict a favourable outcome of phlebectomies, should be further investigated. The treatment of tributaries by phlebectomies and UGFS has been practiced for many years. The current EVTA therapies seem to be less useful in treating tributaries. EVLA and segmental RFA are usually not indicated because of tortuosity of the tributaries. EVSA, however, may be useful for treating tributaries because of the following reasons. First, the catheter is very flexible, second, steam reaches several centimetres and third, EVSA can be used for deeper veins that are not visible and palpable and con-
Table I. Advantages and disadvantages of the different endovenous thermal treatments.

\begin{tabular}{|c|c|c|c|c|c|}
\hline Characteristics & EVLA & RFA & EVSA & MOCA & $\mathrm{CA}$ \\
\hline Effective & +++ & +++ & $++\#$ & $++\#$ & $++\#$ \\
\hline Major complications & $+/-$ & $+/-$ & $+/-$ & $+/-$ & $+/-$ \\
\hline $\begin{array}{l}\text { Device-related } \\
\text { complications }\end{array}$ & + & + & $+/-$ & $?$ & $?$ \\
\hline $\begin{array}{l}\text { High patient satis- } \\
\text { faction/preference }\end{array}$ & ++ & +++ & +++ & +++ & +++ \\
\hline $\begin{array}{l}\text { Standardized } \\
\text { procedure }\end{array}$ & + & ++ & ++ & ++ & ++ \\
\hline \multicolumn{6}{|l|}{ Costs } \\
\hline Generator/laser & + & + & + & - & - \\
\hline Disposables & $+/-$ & ++ & + & ++ & +++ \\
\hline $\begin{array}{l}\text { Treatment of } \\
\text { perforator veins }\end{array}$ & ++ & $+/-$ & ++ & - & $+/-$ \\
\hline $\begin{array}{l}\text { Treatment of } \\
\text { tributaries }\end{array}$ & +- & - & + & - & $+/-$ \\
\hline
\end{tabular}

EVLA: endovenous laser ablation; RFA: radiofrequency ablation; EVSA: endovenous steam ablation; MOCA: mechano-chemical ablation; CA: cyanoacrylate ablation; \#: no long-term evidence yet.

sequently are less suitable for phlebectomies. When after treatment of the tributaries saphenous insufficiency remains, the saphenous vein can be treated at a later stage, if the patient still has complaints.

\section{Conclusions}

Endothermal and non-tumescent ablation of pathological vein reflux have reached a sophisticated level today. These new technologies are able to replace traditional varicose vein surgery and further allow much less invasive treatment in delicate cases.

\section{References}

1. Rutherford RB, Padberg FT, Jr., Comerota AJ, et al. Venous severity scoring: An adjunct to venous outcome assessment. J Vasc Surg 2000;31:1307-12.

2. Smith JJ, Garratt AM, Guest M, et al. Evaluating and improving health-related quality of life in patients with varicose veins. J Vasc Surg, 1999;30:710-9.

3. Launois R, Reboul-Marty J, Henry B. Construction and validation of a quality of life questionnaire in chronic lower limb venous insufficiency (CIVIQ). Qual Life Res 1996:5:539-54.

4. Guex JJ, Zimmet SE, Boussetta S, et al. Construction and validation of a patient-reported outcome dedicated to chronic venous disorders: SQOR-V (specific quality of life and outcome response - venous). J Mal Vasc. 2007;32:135-47.

5. Lamping DL, Schroter S, Kurz X, et al. Evaluation of outcomes in chronic venous disorders of the leg: development of a scientifically rigorous, patient-reported measure of symptoms and quality of life. J Vasc Surg, 2003;37:410-9. 
6. Eklof B, Rutherford RB, Bergan JJ, et al. Revision of the CEAP classification for chronic venous disorders: consensus statement. J Vasc Surg 2004;40:1248-52.

7. van den Bos R, Arends L, Kockaert M, et al. Endovenous therapies of lower extremity varicosities: a meta-analysis. J Vasc Surg 2009;49:230-9.

8. Endovascular Thermal Ablation Technologies for Treatment of Varicose Veins: A Review of Clinical Effectiveness, Safety, CostEffectiveness and Guidelines - An Update [Internet]. Source Ottawa (ON): Canadian Agency for Drugs and Technologies in Health; 2014 Aug.

9. Gloviczki P, Comerota AJ, Dalsing MC, et al. The care of patients with varicose veins and associated chronic venous diseases: clinical practice guidelines of the Society for Vascular Surgery and the American Venous Forum. Society for Vascular Surgery; American Venous Forum. J Vasc Surg. 2011;53:2S-48S.

10. Wittens C, Davies AH, Bækgaard N, et al. Editor's Choice - Management of Chronic Venous Disease: Clinical Practice Guidelines of the European Society for Vascular Surgery (ESVS). Eur J Vasc Endovasc Surg. 2015;49:678-737.

11. van der Velden SK, Pichot O, van den Bos RR, et al. Management Strategies for Patients with Varicose Veins (C2 - C6): Results of a Worldwide Survey. Eur J Vasc Endovasc Surg. 2015; 49:213-20

12. Goldman MP. Closure of the greater saphenous vein with endoluminal radiofrequency thermal heating of the vein wall in combination with ambulatory phlebectomy: preliminary 6-month follow-up. Dermatol Surg 2000;26:452-6.

13. Proebstle TM, Vago B, Alm J, et al. Treatment of the incompetent great saphenous vein by endovenous radiofrequency powered segmental ablation: first clinical experience. J Vasc Surg 2008;47:151-6.

14. Schwarz T, von Hodenberg E, Furtwängler C, et al. Endovenous laser ablation of varicose veins with the $1470-n m$ diode laser. $J$ Vasc Surg. 2010;51:1474-8.

15. Prince EA, Soares GM, Silva M, et al. Impact of laser fiber design on outcome of endovenous ablation of lower-extremity varicose veins: results from a single practice. Cardiovasc Intervent Radiol 2011;34:536-41.

16. Vuylsteke M, Van Dorpe J, Roelens J, et al. Intraluminal fibre-tip centring can improve endovenous laser ablation: a histological study. Eur J Vasc Endovasc Surg 2010;40:110-6.

17. van den Bos RR, Milleret R, Neumann M, Nijsten T. Proof-ofprinciple study of steam ablation as novel thermal therapy for saphenous varicose veins. J Vasc Surg 2010;53:181-6.

18. Almeida JI, Javier JJ, Mackay E, Bautista CM, Proebstle TM. First Human Use of Cyanoacrylate Adhesive For Treatment of Saphenous Vein Incompetence. J Vasc Surg: Venous and Lym Dis 2013;1:174-80.

19. Elias S, Raines JK. Mechanochemical tumescentless endovenous ablation: final results of the initial clinical trial. Phlebology. 2012;27:67-72.

20. ProebstleTM, Gül D, Kargl A, KnopJ. Non-Occlusion and early reopening of the great saphenous vein after endovenous laser treatment is fluence dependent. Dermatol Surg 2004;30: $174-8$

21. Proebstle TM, Moehler T, Herdemann S. Reduced recanalization rates of the great saphenous vein after endovenous laser treatment with increased energy dosing: definition of a threshold for the endovenous fluence equivalent. J Vasc Surg 2006; 44:834-9.

22. Timperman PE, Sichlau M, Ryu RK. Greater energy delivery improves treatment success of endovenous laser treatment of incompetent saphenous veins. J Vasc Interv Radiol. 2004; 15:1061-3.

23. Kabnick LS, Sadek M. Fiber type as compared to wavelength may contribute more to improving postoperative recovery following endovenous laser ablation. J Vasc Surg Venous Lymphat Disord. 2016;4:286-92.

24. Lane TR, Kelleher D, Shepherd AC, et al. Ambulatory varicosity avulsion later or synchronized (AVULS): a randomized clinical trial. Ann Surg. 2015;261:654-61.
25. Malgor RD1, Gasparis AP, Labropoulos N..Morbidity and mortality after thermal venous ablations. Int Angiol. 2016;35:57-61.

26. O'Donnell TF, Eaddy M, Raju A, et al. Assessment of thrombotic adverse events and treatment patterns associated with varicose vein treatment. J Vasc Surg Venous Lymphat Disord. 2015;3:27-34.

27. Pavlović MD, Schuller-Petrović S, Pichot O, et al. Guidelines of the First International Consensus Conference on Endovenous Thermal Ablation for Varicose Vein Disease - ETAV Consensus Meeting 2012. Phlebology 2015;30:257-73.29.

28. Caprini JA. Thrombosis risk assessment as a guide to quality patient care. Dis Mon 2005;51:70-8.

29. Dumantepe M, Uyar I. Comparing cold and warm tumescent anesthesia for pain perception during and after the endovenous laser ablation procedure with $1470 \mathrm{~nm}$ diode laser. Phlebology. 2015;30:45-51.

30. Navarro L, Min RJ, Bone C. Endovenous laser: a new minimally invasive method of treatment for varicose veins-preliminary observations using an $810 \mathrm{~nm}$ diode laser. Dermatol Surg 2001;27:117-22.

31. Min RJ, Zimmet SE, Isaacs MN, Forrestal MD. Endovenous laser treatment of the incompetent greater saphenous vein. $J$ Vasc Interv Radiol 2001:12:1167-71.

32. Mundy L, Merlin TL, Fitridge RA, Hiller JE. Systematic review of endovenous laser treatment for varicose veins. Br J Surg 2005;92:1189-94.

33. Pannier F, Rabe E. Endovenous laser therapy and radiofrequency ablation of saphenous varicose veins. J Cardiovasc Surg (Torino) 2006;47:3-8.

34. Min RJ, Khilnani N, Zimmet SE. Endovenous laser treatment of saphenous vein reflux: long-term results. J Vasc Interv Radiol 2003:14:991-6.

35. Agus GB, Mancini S, Magi G. The first 1000 cases of Italian Endovenous-laser Working Group (IEWG). Rationale, and long-term outcomes for the 1999-2003 period. Int Angiol 2006;25:209-15.

36. Ravi R, Rodriguez-Lopez JA, Trayler EA, et al. Endovenous ablation of incompetent saphenous veins: a large single-center experience. J Endovasc Ther 2006;13:244-8.

37. Sadick NS, Wasser S. Combined endovascular laser plus ambulatory phlebectomy for the treatment of superficial venous incompetence: a 4-year perspective. J Cosmet Laser Ther 2007;9:9-13.

38. Rasmussen L, Lawaetz M, Serup J, et al. Randomized clinical trial comparing endovenous laser ablation, radiofrequency ablation, foam sclerotherapy, and surgical stripping for great saphenous varicose veins with 3-year follow-up. J Vasc Surg Venous Lymphat Disord. 2013;1:349-56.

39. van der Velden SK, Biemans AA, De Maeseneer MG, et al. Fiveyear results of a randomized clinical trial of conventional surgery, endovenous laser ablation and ultrasound-guided foam sclerotherapy in patients with great saphenous varicose veins. Br J Surg. 2015 Sep;102(10):1184-94.

40. Doganci S, Demirkilic U. Comparison of $980 \mathrm{~nm}$ laser and baretip fibre with $1470 \mathrm{~nm}$ laser and radial fibre in the treatment of great saphenous vein varicosities: a prospective randomised clinical trial. Eur J Vasc Endovasc Surg 2010;40:254-9.

41. Stokbroekx T, de Boer A, Verdaasdonk RM, et al. Commonly used fiber tips in endovenous laser ablation (EVLA): an analysis of technical differences. Lasers Med Sci. 2014;29:501-7.

42. Hirokawa M, Ogawa $T$, Sugawara $H$, et al. Comparison of $1470 \mathrm{~nm}$ Laser and Radial 2ring Fiber with $980 \mathrm{~nm}$ Laser and Bare-Tip Fiber in Endovenous Laser Ablation of Saphenous Varicose Veins: A Multicenter, Prospective, Randomized, NonBlind Study. Ann Vasc Dis. 2015;8:282-9.

43. Proebstle TM, Alm J, Göckeritz O, et al. Five-year results from the prospective European multicentre cohort study on radiofrequency segmental thermal ablation for incompetent great saphenous veins. Brit J Surg, 2015;102:212-8.

44. Tesmann JP, Thierbach H, Dietrich A, et al.Radiofrequency induced thermotherapy (RFITT) of varicose veins compared to endovenous laser treatment (EVLT): a non-randomized prospective study concentrating on occlusion rates, side-effects and clinical outcome. Eur J Dermatol 2011:21:945-51. 
45. Goode SD, Chowdhury A, Crockett M, et al. Laser and radiofrequency ablation study (LARA study): a randomised study comparing radiofrequency ablation and endovenous laser ablation (810 nm). Eur J Vasc Endovasc Surg 2010;40:246-53.

46. Newman JE, Meecham L, Walker RJ, Nyamekye IK. Optimising treatment parameters for Radiofrequency Induced Thermal Therapy (RFiTT): A comparison of the manufacturer's treatment guidance with a locally developed treatment protocol. Eur J Vasc Endovasc Surg. 2014;47:664-9.

47. Puggioni A, Kalra M, Carmo M, et al. Endovenous laser therapy and radiofrequency ablation of the great saphenous vein: analysis of early efficacy and complications. J Vasc Surg 2005; 42:488-93.

48. Allegra C, Antignani PL, Carlizza A. Recurrent varicose veins following surgical treatment: our experience with five years follow-up. Eur J Vasc Endovasc Surg 2007;33:751-6.

49. Rass K, Frings N, Glowacki P, et al. Same Site Recurrence is More Frequent After Endovenous Laser Ablation Compared with High Ligation and Stripping of the Great Saphenous Vein: 5 year Results of a Randomized Clinical Trial (RELACS Study). Eur J Vasc Endovasc Surg. 2015;50:648-56.

50. Shepherd AC, Gohel MS, Brown LC, et al. Randomized clinical trial of VNUS ClosureFAST radiofrequency ablation versus laser for varicose veins. Br J Surg 2010;97:810-8.

51. Milleret R, Mehier H, Llopinet A, Camelot G. Oblitération veineuse par vapeur à haute température. Phlebologie 2008;61:223-6.

52. van den Bos RR, Malskat WS, De Maeseneer MG, et al. Randomized clinical trial of endovenous laser ablation versus steam ablation (LAST trial) for great saphenous varicose veins. $\mathrm{Br} J$ Surg. 2014;101:1077-83.

53. Mordon SR, Wassmer B, Zemmouri J. Mathematical modeling of endovenous laser treatment (ELT). Biomed Eng Online 2006;5:26.

54. van Ruijven PW, van den Bos RR, Alazard LM, et al. Temperature measurements for dose-finding in steam ablation. J Vasc Surg 2011;53:1454-6.

55. Proebstle TM, Herdemann S. Early results and feasibility of incompetent perforator vein ablation by endovenous laser treatment. Dermatol Surg 2007;33:162-8.

56. Bootun R, Lane TR, Davies AH. The advent of non-thermal, nontumescent techniques for treatment of varicose veins. Phlebology. 2016;31:5-14.

57. Lane T, Bootun R, Dharmarajah B, et al.. A multi-centre randomised controlled trial comparing radiofrequency and mechanical occlusion chemically assisted ablation of varicose veins - Final results of the Venefit versus Clarivein for varicose veins trial.. Phlebology. 2016; 31:61-5.

58. Almeida JI, Javier JJ, Mackay EG et al. Two-year follow-up of first human use of cyanoacrylate adhesive for treatment of saphenous vein incompetence. Phlebology. 2015;30:397-404.
59. Proebstle TM, Alm J, Dimitri S, et al. The European multicenter cohort study on cyanoacrylate embolization of refluxing great saphenous veins. J Vasc Surg Venous Lymphat Disord. 2015 Jan;31:2-7

60. Morrison N, Gibson K, McEnroe S, et al. Randomized trial comparing cyanoacrylate embolization and radiofrequency ablation for incompetent great saphenous veins (VeClose). J Vasc Surg. 2015;61:985-94.

61. The present status of surgery of the superficial venous system in the management of venous ulcer and the evidence for the role of perforator interruption. O'Donnell, J Vasc Surg 2008).

62. Current state of the treatment of perforating veins. Dillavou ED, Harlander-Locke M, Labropoulos N, Elias S, Ozsvath KJ. J Vasc Surg Venous Lymphat Disord. 2016; 4:131-5.

63. Higorani AP, Ascer E, Marks N, Shiferson A, Patel N, Gopal K, et al. Predictive factors of success following radio-frequency stylet (RFS) ablation of incompetent perforating veins (IPV). J Vasc Surg 2009; 50:844-8.

64. Corcos L, Pontello D, De Anna D, Dini S, Spina T, Barucchello V, et al. Endovenous 808-nm diode laser occlusion of perforating veins and varicose collaterals: a prospective study of 482 limbs. Dermatol Surg 2011;37:1486-98.

65. Cyanoacrylate adhesive perforator embolization (CAPE) of incompetent perforating veins of the leg, a feasibility study. Toonder IM, Lam YL, Lawson J, Wittens CH. Phlebology. 2014; 19:29:49-54

66. Labropoulos N, Giannoukas AD, Delis K, Mansour MA, Kang SS, Nicolaides AN, et al. Where does venous reflux start? J Vasc Surg 1997;26:736-42.

67. Biemans AA, van den Bos RR, Hollestein LM, et al. The effect of single phlebectomies of a large varicose tributary on great saphenous vein reflux. J Vasc Surg Venous Lymphat Disord. 2014:2:179-87.

Submitted: 19.09.2016

Accepted after revision: 07.12.2016

There are no conflicts of interest existing.

Published online: 27.02.2017

\section{Correspondence address}

Prof. Dr. med. Dipl. Phys. Thomas M. Proebstle

Dermatology, Phlebology

Private Clinic Proebstle

P6, 26 (Auf den Planken)

68161 Mannheim

Germany

Thomas.Proebstle@web.de 